\title{
Relationship between electric demand and CDD and the forecast of daily peak electric load in Beijing
}

\author{
D. P. Ding, Z. Xie, X. Li, H. L. You \& C. Han \\ Beijing Meteorological Bureau, People's Republic of China
}

\begin{abstract}
The CDD (Cooling Degree Days) are correlated to the electric demand with the coefficient of $0.56(a=0.01)$ during Jun. to Sept., 1951-2004. It shows that the variation of CDD can reflect the trend of electric demand greatly. So the energy consumption will follow the increasing trend of CDD in summer in future.

The relationship between daily CDD and the electric peak load (Jun.-Sept., 2002-2004) was analyzed by a multiple regression model. It shows that with a 1 degree day increasing of CDD, the daily peak electric load increases by 798 , 1058, 1062 and $479 \mathrm{MW}$ respectively in each month from Jun. to Sept. According to the next day's CDD and the peak electric load of the day before, the next day's peak electricity load could be forecasted by the multiple regression models in summer.

Keywords: CDD, electric demand, daily peak electric load.
\end{abstract}

\section{Introduction}

The Impacts of weather and climate on energy consumption have recently received much attention. Some of them are related to economic losses, others bring profits. Weather has a significant impact on different sectors of the economy. One of the most sensitive sectors is the electricity market, because electric demand is linked to several weather variables, mainly to the air temperature. It is important to understand and be able to predict the effects of weather variables on electric load in order to manage effectively the generation and supply of electricity. Otherwise, studying the electric load behavior in advance is crucial in planning, analysis and operation of power systems so as to assure an uninterrupted, reliable, secure and economic supply of electricity. Both 
for economic and environmental reasons, accurate forecasting of electricity demand is vital. To meet these needs, a long-term forecasting tool for the electric demand and the short-term forecasting tool for daily peak electric load have been developed and tested in this paper.

\section{The definition and variability of CDD (cooling degree days)}

The degree-days index is a quantitative index demonstrated to reflect the demand for energy to heat or cool houses and businesses. A CDD is calculated by subtracting $18^{\circ} \mathrm{C}$ (base temperature in Beijing, China.) from a day's average temperature. The annual or monthly CDD (1951-2004) is the accumulated CDD of each day in that month or year recorded at Beijing Weather Observatory, China. The mean monthly maximum CDD is 259.2 degree days (Jul.). All CDD in Jan., Feb., Mar., Nov. and Dec. are zero in Beijing.

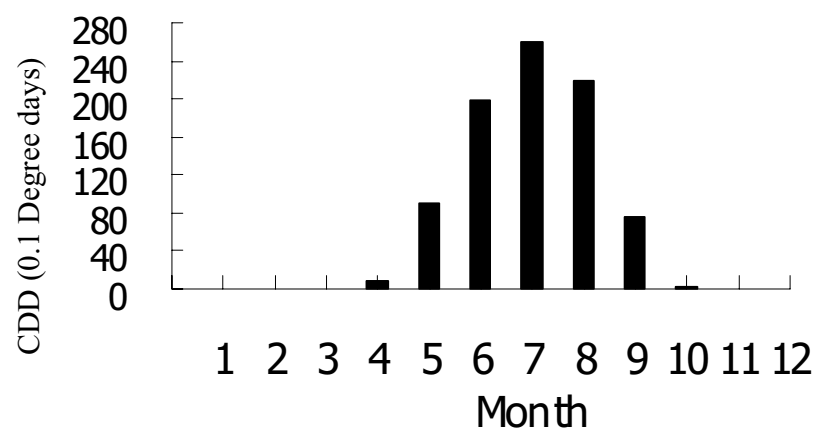

Figure 1: The mean monthly CDD values (1951-2004) in Beijing.

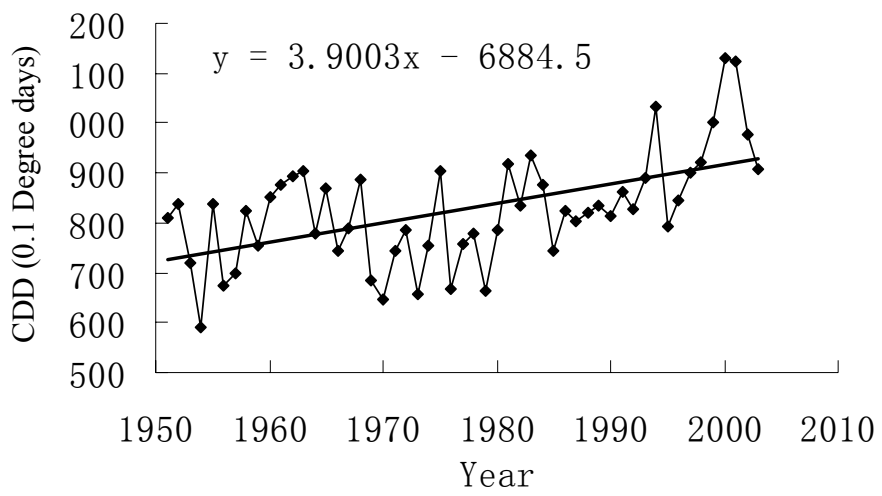

Figure 2: $\quad$ Long-term course of CDD in Beijing in the period of 1951-2004 with the linear trend. 
The mean annual value of CDD, namely mean value of CDD in warm season (May-Sept.1951-2004), is 815.0 degree days. The maximum CDD is 1063.3 degree days (2000). The minimum CDD is 572.0 degree days (1976). There is an increasing trend of 39.0 degree days per decade, which could be interpreted as a climate warming in Beijing during the last $54 \mathrm{yr}$. The annual CDD are highly correlated with the annual temperatures, the correlation coefficient is 0.8 . The annual, decadal mean CDD variations are in phases with the variations of annual, decadal mean temperatures. So the annual CDD estimates accumulated warmth during the warm season as well as the cooling energy consumption within warm season. The larger the CDD is, the more the electricity consumption is in summer in future. The energy consumption will follow the increasing trend of CDD.

\section{Relationship between annual electricity demand and CDD (1951-2004)}

The annual CDD and electricity demand were related with the 0.56 correlation coefficient, which passed the F-statistic test at the $1 \%$ level of significance from Fig. 3. An available overview of the range of electric demand and CDD in the period of 1951-2003 is given in Fig. 3. The liner regression model was performed by the data, LOAD (electric demand) $=38691+5.95$ CDD. So the future annual electric demand could be forecasted by this regression model. The annual electric demand forecast is useful for strategic planning of power, city and environment planning of government.

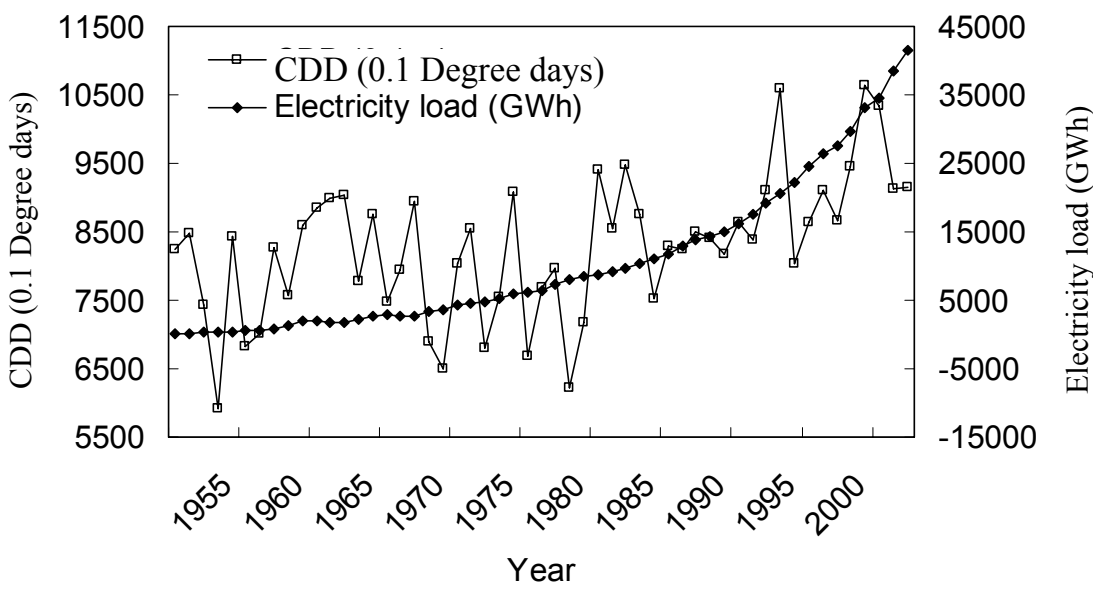

Figure 3: The profiles of CDD and electric demand in Beijing in the period of 1951-2003. 


\section{Variation of daily peak electric load and CDD}

The severe hot weathers occur frequently in summer in Beijing. Hot day is a challenge for electric supply system. Daily electricity peaks would be more adequate to analyze the existence of electricity consumption. In order to avoid the risk of power cut, the relationship between CDD and peak electric load for short-term is studied in this paper. The daily peak electric load and CDD 1/5/2002-30/9/2004 are shown in Fig.4.

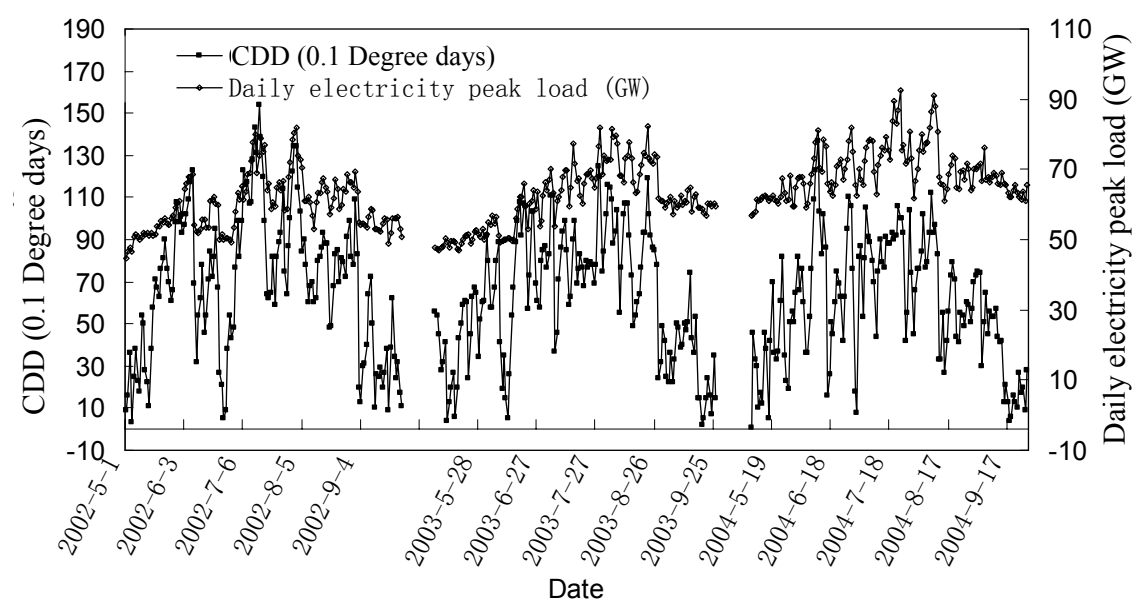

Figure 4: Daily profile of peak electric load for the period 1/5/200230/9/2004.

The daily peak electric loads coincide evidently with daily CDD from Fig. 4. There are three period of peak electric loads. The first peak load is $80.1 \mathrm{GW}$, the corresponding CDD is 13.1 degree days in the first period (Jul. 12, 2002). The second peak load is $82.2298 \mathrm{GW}$, the corresponding CDD is 11.69 degree days (Aug. 22, 2003). The third is $92.5159 \mathrm{GW}$ and CDD is 10 degree days (Jul 23, 2004). The saturation point reaches in 10 CDD. It means that if CDD is more than 10 degree days in summer, the safety measures would be taken to prevent the supply system from being broken.

\section{Forecasting of daily peak electric load}

People are more interesting in short-term forecasting of electric load. Electric demand forecasting is becoming an essential tool for energy management, maintenance scheduling and investment decisions in the future. A quantitative forecasting tool is needed. Multiple linear regressions were estimated for forecasting of daily peak electricity load from Jun. to Sept. by the data. The forecasting equations of daily peak electricity load from Jun. to Sept. are presented as follows: 
DAILY PEAK LOAD (Jun.) $=1085.19+7.98 *$ CDD + 0.73*LOAD $(-1)$

DAILY PEAK LOAD (Jul. $)=1897.23+10.58 *$ CDD + 0.60 *LOAD $(-1)$

DAILY PEAK LOAD (Aug.) $=1543.79+10.61 *$ CDD + 0.66*LOAD $(-1)$

DAILY PEAK LOAD $($ Sept. $)=1140.39+4.79 *$ CDD $+0.78 * \operatorname{LOAD}(-1)$

where DAILY PEAK LOAD is a peak electricity load for a day, CDD is the variable with the same day of DAILY PEAK LOAD, LOAD(-1) is the electric peak load of the day before. The equations show that with 1 degree day increasing of CDD, the daily power peak load increases 798, 1058, 1062 and 479 MW respectively in each month from Jun. to Sept. According to the next day's CDD and the peak electric load of the day before, the next day's peak electric load could be forecasted by the models.

\section{The experiment of Forecasting peak electric load}

Last summer, at the beginning of Jul. 2006, the Beijing Weather Information Office announced the severe hot weather would be coming, and the CDD would reach 14 degree days. In consequence, the peak electric load was $103.1 \mathrm{GW}$, the corresponding CDD was 15 degree days. And on Aug. 6th, the office forecasted there would appear a peak electric load on next 2-3 day again. The second peak electricity load (108.1GW, 14.8 degree days) came on Aug. 8th. Beijing's electric supply system passed the hot weather period safely. The two experiments proved that the models can be applied to the operational forecast of electricity load.

\section{References}

[1] Thom H.C.S. Seasonal Degree-day Statistics for the Unite States. Mon. Wea. Rev., 1952, 80 (9): 143 147.

[2] Enric V. Daily Air Temperature and Electricity load in Spain. 2001 American Meteorological Society. August 2001 1413-1421.

[3] Z. Xie Characteristics of Heating Degree Days and Cooling Degree Days in Beijing. IAMAS 2-11 August 2005, Beijing, China .

[4] J. Wibig . Heating Degree Days and Cooling Degree Days Variability in Loze in The period 1931-2000. Fifth International Conference on Urban Climate. 1-5 September 2003, loze, Poland, 471-474.

[5] Mikdat Kadioglu and Zekai Sen. Degree-day Formulation and Application in Turkey. Journal of Applied Meteorology. Jun. 1999, 837-846. 